\title{
REVIEW
}

Open Access

\section{Dominant optic atrophy}

\author{
Guy Lenaers ${ }^{1 *}$, Christian Hamel ${ }^{1,2}$, Cécile Delettre ${ }^{1}$, Patrizia Amati-Bonneau ${ }^{3,4,5}$, Vincent Procaccio ${ }^{3,4,5}$, \\ Dominique Bonneau ${ }^{3,4,5}$, Pascal Reynier ${ }^{3,4,5}$ and Dan Milea ${ }^{3,4,5,6}$
}

\begin{abstract}
Definition of the disease: Dominant Optic Atrophy (DOA) is a neuro-ophthalmic condition characterized by a bilateral degeneration of the optic nerves, causing insidious visual loss, typically starting during the first decade of life. The disease affects primary the retinal ganglion cells (RGC) and their axons forming the optic nerve, which transfer the visual information from the photoreceptors to the lateral geniculus in the brain.

Epidemiology: The prevalence of the disease varies from 1/10000 in Denmark due to a founder effect, to 1/30000 in the rest of the world.

Clinical description: DOA patients usually suffer of moderate visual loss, associated with central or paracentral visual field deficits and color vision defects. The severity of the disease is highly variable, the visual acuity ranging from normal to legal blindness. The ophthalmic examination discloses on fundoscopy isolated optic disc pallor or atrophy, related to the RGC death. About 20\% of DOA patients harbour extraocular multi-systemic features, including neurosensory hearing loss, or less commonly chronic progressive external ophthalmoplegia, myopathy, peripheral neuropathy, multiple sclerosis-like illness, spastic paraplegia or cataracts.
\end{abstract}

Aetiology: Two genes (OPA1, OPA3) encoding inner mitochondrial membrane proteins and three loci (OPA4, OPA5, OPA8) are currently known for DOA. Additional loci and genes (OPA2, OPA6 and OPA7) are responsible for X-linked or recessive optic atrophy. All OPA genes yet identified encode mitochondrial proteins embedded in the inner membrane and ubiquitously expressed, as are the proteins mutated in the Leber Hereditary Optic Neuropathy. OPA 1 mutations affect mitochondrial fusion, energy metabolism, control of apoptosis, calcium clearance and maintenance of mitochondrial genome integrity. OPA3 mutations only affect the energy metabolism and the control of apoptosis.

Diagnosis: Patients are usually diagnosed during their early childhood, because of bilateral, mild, otherwise unexplained visual loss related to optic discs pallor or atrophy, and typically occurring in the context of a family history of DOA. Optical Coherence Tomography further discloses non-specific thinning of retinal nerve fiber layer, but a normal morphology of the photoreceptors layers. Abnormal visual evoked potentials and pattern ERG may also reflect the dysfunction of the RGCs and their axons. Molecular diagnosis is provided by the identification of a mutation in the OPA1 gene (75\% of DOA patients) or in the OPA3 gene (1\% of patients).

Prognosis: Visual loss in DOA may progress during puberty until adulthood, with very slow subsequent chronic progression in most of the cases. On the opposite, in DOA patients with associated extra-ocular features, the visual loss may be more severe over time.

Management: To date, there is no preventative or curative treatment in DOA; severely visually impaired patients may benefit from low vision aids. Genetic counseling is commonly offered and patients are advised to avoid alcohol and tobacco consumption, as well as the use of medications that may interfere with mitochondrial metabolism. Gene and pharmacological therapies for DOA are currently under investigation.

\footnotetext{
* Correspondence: guy.lenaers@inserm.fr

${ }^{1}$ Institut des Neurosciences de Montpellier, U1051 de I'INSERM, Université de Montpellier I et II, BP 74103, F-34091 Montpellier cedex 05, France Full list of author information is available at the end of the article
} 


\section{Review}

\section{Disease name/synonyms}

DOA: Dominant Optic Atrophy (OMIM \#165500), initially called Kjer's Optic Atrophy, was first described by the Danish ophthalmologist Dr. Poul Kjer [1]. DOA is also called Autosomal Dominant Optic Atrophy (ADOA), to emphasize its autosomal mode of inheritance, in contrast with Leber Hereditary Optic Neuropathy (LHON), inherited by mutations on the mitochondrial genome and maternal lineage.

DOAD-DOAplus: Dominant Optic Atrophy and Deafness and DOAplus (both OMIM \#125250) are syndromic forms of DOA associating neurosensory deafness (DOAD) and/or other clinical manifestations (DOAplus) like myopathy, progressive external ophthalmoplegia, peripheral neuropathy, stroke, multiple sclerosis or spastic paraplegia.

DOAC: Dominant Optic Atrophy and Cataract (OMIM \#606580) is a rare form of DOA associated to cataract.

Orphanet reference numbers are ORPHA98673 for DOA, and ORPHA1215 for DOAplus.

\section{Definition}

DOA is an optic neuropathy due to the degeneration of optic nerve fibers. It belongs to the group of inherited optic neuropathies (ION), which are genetic conditions affecting the retinal ganglion cells (RGCs) whose axons form the optic nerve. Because RGCs are neurons originating from an extension of the diencephalon, DOA is a disease of the central nervous system [2].

DOA is a mitochondriopathy, as the genes responsible for DOA encode proteins ubiquitously expressed, imported into the mitochondria and associated to the inner membrane [3]. As such, DOA may be syndromic and include extra-ocular symptoms, mostly neuro-muscular, that are frequently found in mitochondriopathies [4].

\section{Epidemiology}

DOA is a relatively common form of inherited optic neuropathy. Its prevalence is $3 / 100,000$ in most populations in the world, but can reach $1 / 10,000$ in Denmark where a founder effect was identified $[5,6]$. DOA penetrance is around $70 \%$, but depending on families, mutations and study criteria [6,7], it can vary from $100 \%$ [5] to 43\% [8]. Syndromic DOAD and DOAplus account for some $20 \%$ of all DOA cases and are fully penetrant [9].

\section{Clinical description}

The disease was first described at the end of the $19^{\text {th }}$ century $[10,11]$. Large families were then reported in UK [12], USA [13] and France [14], but it was after the report of 19 DOA families by the Danish ophthalmologist
Kjer that this clinical entity was recognized and assigned his name [1].

\section{Non syndromic dominant optic atrophy}

In most cases, DOA presents as a non syndromic, bilateral optic neuropathy. Although DOA is usually diagnosed in school-aged children complaining of reading problems, the condition can manifest later, during adult life [15-17]. DOA patients typically experience a slowly progressive, insidious decrease of vision, which can rarely be asymmetric, although rapid decline has also been reported in adults $[18,19]$. The visual impairment is irreversible, usually moderate (visual acuity: $6 / 10$ to $2 /$ 10) and highly variable between and within families. However, extreme severity (legal blindness) or very mild presentation (subclinical decrease in visual acuity) can be encountered $[20,21]$.

On fundus examination, the optic disk typically presents a bilateral and symmetrical pallor of its temporal side, witnessing the loss of RGC fibers entering the optic nerve (Figure 1A). The optic nerve rim is atrophic and a temporal grey crescent is often present. Optic disc excavation is not unusual, but its clinical features vary in most of the cases from that of glaucoma. Optical Coherence Tomography (OCT) discloses the reduction of the thickness of the peripapillary retinal nerve fiber layer in all four quadrants, but does not disclose alteration of other retinal layers [22,23] (Figure 1B). The visual field typically shows a caecocentral scotoma, and less frequently a central or paracentral scotoma, while peripheral visual field remains normal (Figure 1C). Importantly, there is a specific tritanopia, i.e. a blueyellow axis of color confusion, which, when found, is strongly indicative of Kjer disease [24,25] (Figure 1D). However, in severe cases or in patients with congenital dyschromatopsia (daltonism), interpretation of the color vision defect may be more difficult. The pupillary reflex and circadian rhythms are not affected, suggesting that the melanopsin RGC are spared during the course of the disease [26,27].

Some patients harboring the pathogenic OPA1 mutation can be asymptomatic; at the opposite end of the clinical variability spectrum, mutations of the OPA1 gene have been reported to enhance multisystemic deficits while sparing totally the optic nerve.

Anterior and/or posterior blue-dot cerulean cataract occurs in the rare DOA patients with an OPA3 mutation [28].

Although typical DOA is associated with a progressive and irreversible loss of vision, we reported the case of a young man (23 years) who developed an isolated, progressive, painless bilateral optic neuropathy as a result of central scotomas that spontaneously recovered partial vision six months later. The patient harbored a novel 


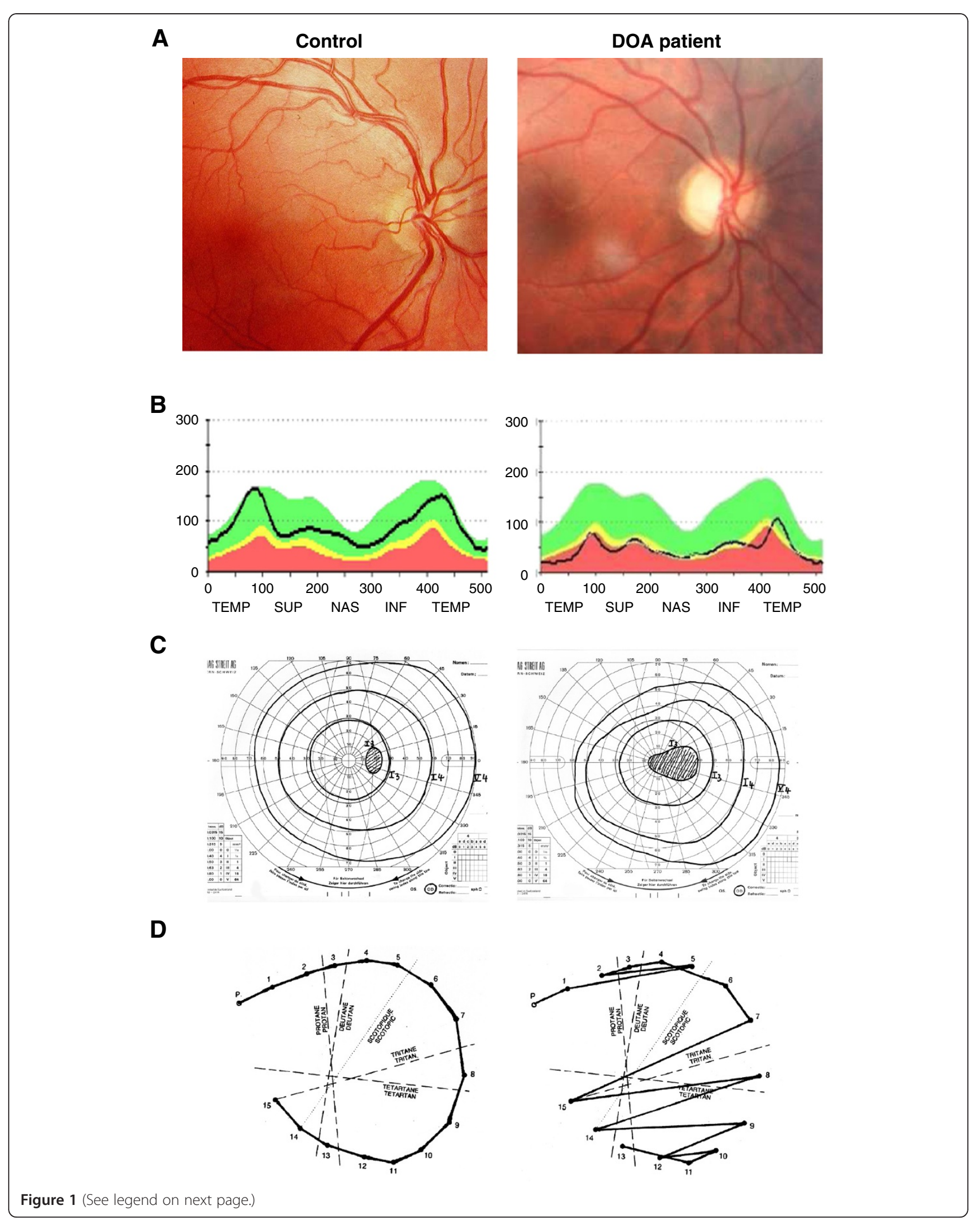


(See figure on previous page.)

Figure 1 Ophthalmological description of a DOA patient. Results from ophthalmological examination of a paradigm Dominant Optic Atrophy patient with the c.2708delTTAG mutation in OPA1 (Right) compared to a control patient (Left). (A): Eye fundus examination showing the pallor of the optic nerve in the DOA patient, in particular on the temporal side, whereas the rest of the retina appears totally unaffected. (B): Optical Coherence Tomography measures of the retinal nerve fiber layer thickness (black line), at the emergence of the optic disc. In a DOA patient, there is a general reduction in all quadrants, prevailing on the temporal side, compared to a control patient. (C): Visual field examination disclosing the caeco-central scotoma in the DOA patient, whereas only the blind spot is detected in control patient. (D): Results from a desaturated 15-Hue test presenting the characteristic tritanopia (blue-yellow axis) dyschromatopsia defect in the DOA patient. heterozygous mutation in OPA1 exon $5 \mathrm{~b}$ (c.740G $>\mathrm{A}$ ) which was the first mutation to be described in one of the three alternative OPA1 exons [29]. In addition, we identified another original case presenting a late onset (62 years) sequencial and acute loss of vision, associated to a novel dominant mutation (c.2794C > T) in OPA1 [30], suggesting that atypical natural histories of DOA can be related to OPA1 mutations.

\section{Syndromic dominant optic atrophy}

Syndromic DOAD and DOAplus patients experience full penetrance and usually more severe visual deficits $[9,31,32]$.

DOAD and DOAplus with extra-ophthalmological abnormalities represent up to $20 \%$ of DOA patients with an OPA1 mutation [6]. The most common extra-ocular sign in DOA is sensori-neural hearing loss, but other associated findings may occur later during life (myopathy and peripheral neuropathy), suggesting that there is a continuum of clinical presentations ranging from a mild "pure DOA" affecting only the optic nerve, to a severe and multisystemic presentations. Sensori-neural hearing loss associated to DOA may range from severe and congenital to subclinical [31-36] with intra- and inter- familial variations, and mostly segregate with the OPA1 $\mathrm{R} 445 \mathrm{H}$ (c.1334G>A) mutation. In general, auditory brain stem responses, which reflect the integrity of the auditory pathway from the auditory nerve to the inferior colliculus, are absent, but both ears show normal evoked oto-acoustic emissions, reflecting the functionality of presynaptic elements and in particular that of the outer hair cells [37].

Peripheral axonal sensory and/or motor neuropathy and proximal myopathy may be diagnosed in some DOA patients from their third decade of life onwards, as well as a combination of cerebellar and sensory ataxia in adulthood, multiple sclerosis-like illness and spastic paraplegia $[9,16,38,39]$. Progressive external ophthalmoplegia is also frequently diagnosed in syndromic DOAplus patients [9]. One report of a Behr syndrome associating DOA to pyramidal signs, ataxia and mental retardation was linked to an OPA1 mutation [40] and another report describing a severe neuromuscular phenotype associated to optic atrophy was described in two OPA1 compound heterozygote siblings [41]. Muscle biopsy from DOAplus patient revealed features typical of mitochondrial myopathy, as approximately $5 \%$ of all fibers were deficient in histochemical COX activity and several fibers showed evidence of subsarcolemmal accumulation of abnormal mitochondria, a phenotype known as ragged red fibers [9,31,32].

\section{Etiology \\ Loci and genes}

DOA is not genetically highly heterogeneous, in comparison with many other ophthalmologic or neurodegenerative disorders (Table 1). The first DOA locus, OPA1, localised on $3 q 28$ was initially considered as unique $[42,43]$. But since the discovery of the OPA1 gene in $2000[44,45]$, two other loci, OPA4 and OPA5, were further identified in few families ( 1 for OPA4 and 2 for OPA5) presenting pure DOA [46,47]. Additional loci and genes were identified as responsible for Optic Atrophy, but either with a X-linked mode of inheritance (OPA2) $[48,49]$, a recessive mode of inheritance (OPA6 and OPA7) [50,51] or as syndromic recessive or dominant forms (OPA3 and OPA8) [28,52,53]. Thus to date, OPA1 is the major gene responsible for DOA, accounting for at least $75 \%$ of all the patients, whereas all the other genes or loci only contribute each for less than $1 \%$ of the patient cohort [7].

\section{Mutations in OPA genes and their consequences on the mitochondrial physiology}

Three genes have been identified to date, OPA1, OPA3 and TMEM126A (OPA7) (Table 1); all encode mitochondrial

Table 1 DOA loci and genes

\begin{tabular}{llll}
\hline Locus & Chromosome & Gene & Mode of inheritance \\
\hline OPA1 & $3 q 28-29$ & OPA1 & dom. \\
OPA2 & Xp11.4-p11.21 & $?$ & X-link \\
OPA3 & $19 q 13.2-q 13.3$ & OPA3 & dom./ress. \\
OPA4 & $18 q 12.2-q 12.3$ & $?$ & dom. \\
OPA5 & $22 q 12.1-q 13.1$ & $?$ & dom. \\
OPA6 & $8 q 21-q 22$ & $?$ & ress. \\
OPA7 & $11 q 14.1-q 21$ & TMEM126A & ress. \\
OPA8 & $16 q 21-q 22$ & $?$ & dom. \\
\hline
\end{tabular}

legend: dom: dominant; ress: recessive. 
proteins ubiquitously expressed and associated to the inner mitochondrial membrane, due to the presence of at least one transmembrane domain in their sequence $[51,54,55]$. In OPA $1,27 \%$ of the mutations are missense, $27 \%$ are splice variant, $23.5 \%$ lead to frame shift, $16.5 \%$ are nonsense and $6 \%$ are deletion or duplication [7]. Most of them are leading to a haplo-insufficiency situation where the mutated transcript is degraded by mRNA decay, thus leading to a reduction of $50 \%$ in the amount of OPA1 protein. As a direct consequence, the different mutations in OPA1 are not related to the severity of the disease, and genotype/phenotype correlations are difficult to infer [25]. In this respect, secondary nuclear genes, but not the mitochondrial genome, are suspected to control the severity of the disease in non-syndromic patients [56]. Conversely, few missense mutations in the GTPase domain of OPA1 are responsible for syndromic cases with severe dominant negative effects [9], because the mutated protein might interfere with and inhibit the wild-type protein. Importantly, sporadic cases, cases with de novo mutation and cases with unknown familial history, account together for $50 \%$ of all patients. Concerning OPA3, indirect evidences suggest that the 2 mutations so far reported in DOAC affect the trans-membrane domain, are fully penetrant and act in a dominant negative manner, as heterozygous carriers of a recessive mutation leading to the inhibition of OPA3 expression are asymptomatic [52]. In the case of TMEM126a, the consanguineous recessive disease is associated to a mutation introducing a stop codon at position 55, thus deleting 140 out of the 195 amino-acids composing the protein [51].

Analysis of OPA1 functions in common cell lines (HeLa, COS) and dysfunctions in patient fibroblasts revealed a systematic susceptibility to apoptosis and mild to severe alteration of the mitochondrial respiration activity, essentially associated to a reduced energetic coupling [28,51,57-60]. In addition, the 8 OPA1 isoforms that result from alternate splicing of 3 exons (4, $4 b$ and $5 b$ ) have discrete functions in structuring the cristae, in mitochondrial membrane dynamics, maintenance of the membrane potential, calcium clearance, interaction with the respiratory chain complexes and maintenance of mitochondrial genome integrity [61-65]. As a consequence, and as revealed by numerous patient fibroblast studies, mutations in OPA1 can have a direct although variable impact on these functions, [31,33,57-59,66], and possibly the genetic background and aging might contribute to the mitochondrial phenotype, either in a compensatory or in an accentuating manner.

Importantly, the OPA1 gene is the fifth identified nuclear gene responsible for generating multiple deletions in the mitochondrial DNA, together with POLG1 (DNA polymerase $\gamma$ ), PEO1 (twinkle), SLC25A4 (ANT1) and TP (thymidine phosphorylase). The presence of multiple deletions in the mtDNA has been found in the skeletal muscle of the majority of patients harbouring OPA1 mutations, even in those with isolated optic atrophy [67]. This OPA1 related genomic instability is likely to play a crucial role in the pathophysiology of DOA, taken into account its direct functional consequence on respiratory chain capacities and may explain the convergence of clinical expressions between DOAplus syndromes and other disorders related to mutations in mtDNA.

\section{Optic nerve and animal models}

The major concern in studying DOA pathophysiology concerns the question why RGCs are most specifically affected by this disease, while the OPA genes are expressed in all cells of the body. Histochemical studies revealed a peculiar distribution of mitochondria in retinal ganglion cells. Indeed, they are accumulated in the cell bodies and in the intra-retinal unmyelinated axons, where they form varicosities, and are conversely scarce in the myelinated part of axons after the lamina cribosa [68-71]. These observations emphasize the importance of mitochondrial network dynamic in order to maintain the appropriate intracellular distribution of the mitochondria that is critical for axonal and synaptic functions, and point to a possible pathophysiological mechanism associated to OPA1 that could jeopardize RGC survival. Alternatively, RGCs are the only neurons of the body that are exposed to the day long stress of light, which generates oxidative species favoring the apoptotic process [72]. Therefore the mitochondrial fragility conferred by OPA1 mutations, together with the photo-oxidative stress could precipitate RGCs in premature cell death. A third pathophysiological hypothesis involves the tremendous energetic requirements of RGCs, as these neurons permanently fire action potentials, in addition through axons that are not myelinated in the eye globe. As the energetic fuelling of RGCs soma is restricted in the central part of the retina, due to the physical constraints imposed by the macula blood vessel organization, one can hypothesize that due to the uncoupling of mitochondrial respiration in OPA1 cells, the ATP synthesis in patient RGCs is limited and can not fulfill the physiological energetic requirements for long term cell survival. Which of these hypotheses represents the princeps mechanism responsible for the RGC degeneration remains unknown. Nevertheless, in the last years, two mouse models with an Opa1 mutation have been generated and deeply analyzed in terms of vision; both summarize DOA in that loss of RGCs is preeminent [73,74]. Reduction of the scotopic, but not the photopic evoked 
potential response was found in one mouse model [75], whereas light-adapted ERG and VEP responses revealed a significant reduction in their amplitudes in another mouse model [76]. Histological examinations revealed a decrease of the dentritic length of the RGC-On subpopulation in the retina [77], and abnormal myelin structures, increase in micro-glia and autophagy were noticed in the optic nerve [78]. In addition, some mild neuromuscular symptoms were found, as locomotor activity was reduced and tremor observed in old animals, but no alteration of the audition was detected [79], thus these Opa1 animals show some features of the syndromic DOA forms.

\section{Diagnostic methods \\ Anamnesis}

Interviewing patients about the natural history of the disease, at best in the presence of the family, is mandatory to define the timing of visual loss over time. Suspicion of DOA prompts also the search of similar visual signs among relatives. Special attention should be paid on sensorial or peripheral neuropathy symptoms that would support the hypothesis of a pathophysiology related to a mitochondrial deficit. Finding at least one affected member in two consecutive generations is indicative of a dominant trait, or eventually of a mitochondrial maternal transmission, that will further orientate the genetic investigations.

\section{Ophthalmological examination}

DOA is characterized by a bilateral symmetric vision loss. On funduscopic examination, the cardinal sign consists in an optic nerve pallor usually bilateral and symmetric on the temporal side in about $50 \%$ of patients and global in the other 50\% [80], especially in old or severely affected patients. In moderate cases, the optic nerve atrophy may not be visible. The neuroretinal rim is often pale and sometimes associated with a temporal pigmentary grey crescent. OCT examination discloses and quantifies the thinning of the fiber layer in the 4 cardinal directions at the optic nerve rim $[23,81]$. Profound papillary excavation is reported in $21 \%$ of eyes from OPA 1 patients [82]. Visual fields examination typically reveals a central, centrocecal or paracentral scotoma, which may be large in severely affected individuals, and the sparing of the peripheral visual field [20]. Color vision, evaluated by the desaturated 15-Hue test discloses often a blueyellow loss dyschromatopsy, or tritanopia [25].

\section{Electrophysiological assessment}

Visual evoked potentials (VEPs) are typically absent or delayed, but are not characteristic of the disease. In subclinical or mildly affected patients, no alteration of the
VEPs can be found. Pattern electroretinogram (PERG) shows an abnormal N95:P50 ratio, with reduction in the amplitude of the N95 waveform suggesting alterations of the ganglion cells layer [83].

\section{Genetic investigations}

The clinical diagnosis of an optic atrophy will orientate the genetic investigations. After collecting $5 \mathrm{ml}$ of blood of the patient and its relatives and preparing total DNA, the analysis of OPA1 gene will be performed on the DNA sample of the index patient by amplifying and sequencing all the 31 coding exons and their flanking intronic regions. If a mutation is identified, its segregation in the family must be analyzed and its identity has to be compared to the database hosted by the CHU of Angers, France (http:// lbbma.univ-angers.fr/lbbma.php?id=9) to find out if the mutation is already recognized as pathogenic. If not, the possible consequence of the mutation on OPA1 transcript and protein integrity should be analyzed in silico, and by assessing the expression of the mutated allele by RT-PCR amplification and sequencing. If no significant mutation is found in OPA1, then the presence of a deletion in the gene can be tested with the Multiplex Ligation Probe Amplification methodology [84-86]. Otherwise careful reconsideration of the anamnesis might orientate to test either OPA3 gene or the full length mitochondrial genome. If results are still negative, then when the family is large and many members are affected, genetic analysis of chromosome markers can be performed to identify the causative locus and eventually a novel pathogenic gene. Nevertheless, the identification of a morbid mutation greatly helps the genetic counseling.

\section{Syndromic cases}

Patients with extra-ophthalmological symptoms should be referred to diagnostic centers specialized in mitochondrial disorders, in order to obtain additional examinations by a multidisciplinary team including geneticists, neuroophthalmologists, neurologists, otorhynolaryngologists.

The diagnosis of such multisystemic mitochondrial disorders often requires the study of the functionality of the respiratory chain in order to evaluate the severity of the energetic deficiency. A skeletal muscle biopsy is usually performed to measure the enzymatic activity of the 5 respiratory complexes and the mitochondrial oxygraphy. In addition, it allows anatomo-pathological examinations to check for the presence of mtDNA deletions, cytochrome $c$ deficient fibers and ragged red fibers. Alternatively, skin fibroblasts are also useful to evaluate the severity of respiratory chain dysfunction.

\section{Differential diagnosis}

The DOA differential diagnosis list includes all the causes of bilateral optic neuropathies, i.e. compressive, 
inflammatory, demyelinating, ischemic, glaucomatous, toxic, and metabolic optic neuropathies. However, an appropriate clinical and para-clinical work-up, including neuro-imaging, biochemical studies or genetic tests, will rule out these causes in most of the cases.

Among these differential diagnosis, normal tension glaucoma (NTG) may present with signs consistent with DOA, such as visual field defects and optic disc excavation. However, NTG occurs late during the adulthood and central visual loss does not occur until late during the course of the disease. Interestingly, certain allelic sequence variants in OPA1 have been found to be more prevalent in NTG patients in comparison with controls, thus suggesting some cross-talk between the pathophysiological mechanisms of these diseases [87].

Other acquired optic neuropathies with similar presenting signs as DOA include the nutritional/toxic optic neuropathies, which may have a mitochondrial dysfunction basis. Among the toxic optic neuropathies, the most common is the tobacco-alcohol related optic neuropathy. Other possible agents causing a toxic optic neuropathy include methylene, ethylene glycol, cyanide, lead, and carbon monoxide. Finally, certain medications, including ethambutol, isoniazid, disulfiram can cause a toxic optic atrophy.

Other hereditary optic neuropathies, such as Leber's hereditary optic neuropathy, Wolfram's syndrome or other neuropathies associated with neurological diseases (spinocerebellar ataxias, Friedreich's syndrome, Charcot Marie-Tooth type 2A, Deafness-Dystonia-Optic Neuropathy syndromes etc.) may, at times, present with similar signs as DOA, though the general context and the neurological signs help to differentiate those entities.

\section{Differential diagnosis associated to the OPA loci}

Athough OPA loci are all primarly associated to optic atrophy, in some cases they can be differentiated by the presence of secondary symptoms (Table 2 ) that may orient toward a particular gene or locus. OPA2: Two families mapping on the OPA2 locus Xp11.4-p11.21 were identified [48], both presented optic atrophy from early childhood [49], and one associated in some instances optic atrophy to mental retardation and neurological symptoms as jerks, dysarthria, dysdiadochokinesia, tremor and gait $[88,89]$. In both families, only male are affected and female carriers showed no abnormalities.

OPA3: Patients presenting dominant mutation in $O P A 3$ gene display an early optic atrophy followed by a later anterior and/or posterior cortical cataract and dyschromatopsy without systematic axis. In some cases, patients present tremor, extrapyramidal rigidity, pes cavus and absence of deep tendon reflex [28]. Patients with OPA3 recessive mutations present the syndromic Costeff syndrome (see next paragraph).

OPA4 and OPA5: three families linked to the OPA4 or OPA5 loci present an optic atrophy that can not be differentiated from the phenotype observed in OPA1 patients: i.e. optic nerve pallor, decreased visual acuity, color vision defects, impaired VEP, and normal ERG and no extra-ocular findings $[46,47]$.

OPA6 and OPA7: Recessive forms of optic atrophy were described linked to the OPA6 and OPA7 loci. OPA6 patients present an early onset optic atrophy slowly progressing with a red-green dyschromatopsia [50]. Concerning OPA7, a severe juvenile-onset optic atrophy with central scotoma was found in a large multiplex inbred Algerian family and subsequently in three other Maghreb families with the same mutation in the TMEM126A gene, suggesting a founder effect. In these family, some patients presented mild auditory alterations and hypertrophic cardiopathy [51].

OPA8: One large family with a optic atrophy undistinguishable from that related to OPA1 was recently described. In this family late-onset sensorineural hearing loss, increases of central conduction times at somatosensory evoked potentials, and various cardiac abnormalities were also described in some patients [53].

\section{DOA differential diagnosis with other hereditary optic neuropathies}

Leber Hereditary Optic Neuropathy (LHON) is the major differential diagnosis for optic atrophy type 1 (OPA1). LHON typically presents in young adults as

Table 2 Possible symptoms associated to optic atrophy

\begin{tabular}{|c|c|c|c|c|c|c|c|}
\hline Locus & OpticAtrophy & Deafness & Poly neuropathy & Multiple Sclerosis & Myopathy CPEO & Cardiopathy & Cataract \\
\hline OPA1 & + & $+/-$ & $+\backslash-$ & $+\backslash-$ & $+\backslash-$ & - & - \\
\hline OPA2 & + & - & - & - & - & - & - \\
\hline OPA3 & + & - & $+\backslash-$ & - & - & - & + \\
\hline OPA4 & + & - & - & - & - & - & - \\
\hline OPA5 & + & - & - & - & - & - & - \\
\hline OPA6 & + & - & - & - & - & - & - \\
\hline OPA7 & + & $+\backslash-$ & - & - & - & $+\backslash-$ & - \\
\hline OPA8 & + & $+\backslash-$ & - & - & - & $+\backslash-$ & - \\
\hline
\end{tabular}

legend: (+): systematic; (+/-): possible; (-): never reported. 
painless acute or subacute visual failure, occurring sequentially in both eyes, within six months. The acute phase begins with blurring of central vision and color desaturation. The central visual acuity deteriorates to the level of counting fingers in up to $80 \%$ of cases, associated with a large centrocecal scotoma. In few cases, in particular in patients with the m.14484 G > A mutation, visual acuity may partially improve over time. Males are more commonly affected than females and women tend to develop the disorder slightly later in life and may be more severely affected, sometimes with associated multiple sclerosis like symptoms. Other neurologic abnormalities, such as a postural tremor or the loss of ankle reflexes are also found. LHON is maternally inherited by mutation in the mitochondrial genome, in most patients (95\% of cases) by one of the three mutations m.11778G > A, m.14484T > C, and m.3460G > A [90].

\section{Differential diagnosis between syndromic DOA and other diseases}

Wolfram syndrome Mutations in the WFS1 gene are generally associated with optic atrophy as part of the autosomal recessive Wolfram syndrome phenotype (DIDMOAD, diabetes insipidus, diabetes mellitus, optic atrophy, deafness) [91,92] or with autosomal dominant progressive low-frequency sensori-neural hearing loss that can be associated with DOA, with or without impaired glucose regulation [93,94], supporting the notion that mutations in WFS1 as well as in OPA1 may lead to optic atrophy combined with hearing impairment.

Costeff syndrome Truncating mutations in OPA3 gene are responsible for 3-methylglutaconic aciduria type 3, a recessive neuro-ophthalmologic syndrome consisting of early-onset bilateral optic atrophy and later-onset spasticity, extra-pyramidal dysfunction, and cognitive deficit. Urinary excretion of 3-methylglutaconic and 3-methylglutaric acids is increased [52,95].

Charcot-Marie-Tooth type $\mathbf{2 A 2}$ (CMT2A) is a peripheral distal neuropathy with optic atrophy designated as hereditary motor and sensory neuropathy type VI (HMSN VI) [96]. HMSN VI families display subacute onset of optic atrophy and subsequent slow recovery of visual acuity in $60 \%$ of affected individuals. In each pedigree a dominant mutation in the MFN2 gene coding the outer mitochondrial dynamin mitofusin 2, was identified [97]. Recently a novel mutation in MFN2 as been described in a patient with a DOAplus clinical presentation, featuring also mtDNA deletions in the calf muscle [98].

Deafness-dystonia-optic neuronopathy syndrome (DDON) is a disease associating slowly progressive decreased visual acuity from optic atrophy beginning at about 20 years of age with neuro-sensorial hearing impairment, slowly progressive dystonia or ataxia and dementia beginning at about 40 years of age. Neurologic, visual, and neuropsychiatric symptoms vary in degree of severity and rate of progression [99]. As the inheritance is $\mathrm{X}$-linked, males are only affected, although females may present mild hearing impairment and focal dystonia. The DDON syndrome is linked to mutation in TIMM8A or to a deletion at Xq22, also causing X-linked agammaglobulinemia due to the disruption of the $B T K$ gene located telomeric to TIMM8A [100].

\section{Other inherited disorders of Oxidative Phosphorylation}

Mitochondrial diseases featuring a defect in the respiratory chain affect about 1/4000 individuals. They include clinical presentations with widely differing genetic origin and phenotypic expression. Their clinical expression is mainly neuromuscular and neurosensorial, but the major physiological systems and functions may also be affected. More than a hundred pathogenic mutations have been described in mitochondrial DNA since 1988, and new mutations are still regularly being reported. MtDNA mutations may be secondary to the mutations of nuclear genes encoding the proteins that ensure the maintenance of mtDNA. Since 1995, more than 70 nuclear genes have been involved in respiratory chain defects. The clinical defects identified in DOAplus (deafness, peripheral neuropathy, chronic external ophthalmoplegia, myopathy, encephalopathy, multiple sclerosis-like syndromes) are typical of those found in multisystemic mitochondrial diseases that often themselves include optic atrophy. Thus, facing a multisystemic mitochondrial syndrome with optic atrophy it is important to check for OPA1 mutations, but many other mitochondrial diseases not related to OPA1 can also display a clinical presentation similar to DOAplus, as recently evidenced by the discovery of a singular mis-sense mutation in the MFN2 gene leading to a DOAplus phenotype [98]. Interestingly, in a few cases, the clinical presentations of OPA1 mutations excluded optic nerve involvement $[9,101]$, suggesting that rare OPA1-associated diseases may tend towards clinical phenotypes far removed from the initial description of DOA.

\section{Genetic counseling}

DOA is inherited as an autosomal dominant trait. When the causative mutation has been identified either in $O P A 1$ or OPA3 genes, it should be present in one of the parents except in de novo cases, and will be transmitted with a $50 \%$ chance to the proband sibs. When the causative mutation is not identified, genetic analysis can be performed on the family if other members are affected, in order to localize the locus responsible for the disease. Nevertheless, in these latter cases, results might not 
be straightforward and genetic counseling could remain doubtful. Otherwise, when facing simplex proband without known gene etiology, no genetic counseling can be provided. Importantly, in isolated cases, de novo mutations were frequently reported in OPA1 gene, allowing consequently to provide advises for family projections. In this respect, prenatal diagnosis for pregnancies at risk is feasible but remains complicated when considering the incomplete penetrance and the markedly variable inter- and intrafamilial expressivity of DOA.

\section{Antenatal diagnosis}

The optimal time for determining genetic risk and sensitizing future parents to genetic testing is obviously before pregnancy. If young adults are affected or at risk, it will be appropriate to discuss the potential risk for their offspring and the reproductive options, as preimplantation genetic diagnosis is available for families in which the disease-causing mutation or locus has been identified. Alternatively, prenatal genetic diagnosis for pregnancies at risk is possible by analysis of DNA extracted from fetal cells obtained by amniocentesis, again when the disease-causing allele in the affected family member has been identified.

Prenatal testing for DOA is controversial and uncommon, especially since the disease does not affect intellectual development or life span. Prenatal testing implies a thorough discussion between the health care professionals and the involved parents.

\section{Management including treatment}

The management of DOA patient consists in regular ophthalmologic examination, including measurement of visual acuity, color vision, visual fields and OCT. To date, no specific treatment exists, but low-vision aids in patients with severely decreased visual acuity can be beneficial. Avoiding tobacco and alcohol intake as well as medications (antibiotics, antivirals) which can interfere with mitochondrial metabolism can be additional prophylactic measures.

Cochlear implants have been shown to restore a marked improved audition in patients with syndromic DOA with neurosensorial deafness [37].

\section{Prognosis}

In most cases, the diagnosis of DOA is established before adulthood. Subsequent visual loss is mild, but can at times worsen acutely, while spontaneous improvement is exceptionally rare. However, patients may develop adaptative strategies, allowing them to fixate within intact retinal regions and thus comply with a normal familial and social life, although insertion in the professional life might be compromised by the visual defect.

Patients with syndromic DOA will experience a more severe visual defect that often will be followed by audition impairment, which together will affect their social communication early in adulthood. Additional symptoms can occur later during the third or fourth decade of life, and are believed to progress slowly.

\section{Unresolved questions and conclusions}

Although OPA1, the major gene responsible for DOA has now been discovered more than ten years ago, much remains to be understood to explain the specificity of the disease that focus first on the optic nerve integrity. Indeed two major challenges are unanswered: the identification of the princeps mechanism that is affected in DOA, and deciphering why mainly RGCs are degenerating in this disease. Answering both of these questions should facilitate the future design of treatments.

The current absence of treatment for DOA raises a tremendous challenge in testing therapeutic strategies on the different available models, from cell lines to animals. It is probably not beyond reasonable hope to think that in the next ten years, treatments will be found to restrain the RGCs loss in DOA.

\section{Abbreviations}

DOA: Dominant Optic Atrophy; DOAD: Dominant Optic Atrophy and Deafness; DOAplus: syndromic Dominant Optic Atrophy; OPA: Optic Atrophy; LHON: Leber Hereditary Optic Neuropathy; ION: Inherited Optic Neuropathy; NTG: Normal Tension Glaucoma; DDON: Deafness Dystonia and Optic Neuropathy; DIDMOAD: Diabetes Insipidus, Diabetes Mellitus, Optic Atrophy and Deafness; CMT2A: Charcot Marie Tooth type 2A disease; HMSN: Hereditary Motor and Sensory Neuropathy; RGC: Retinal Ganglion Cell; VEP: Visual Evoked Potential; PERG: Pattern ElectroRetinoGram; OCT: Optical Coherence Tomography.

\section{Competing interests}

All authors declare that they have no competing interests.

\section{Authors' contributions}

All authors have contributed to the redaction and correction of the manuscript. All authors read and approved the final manuscript.

\section{Acknowledgements}

We are indebted to the following patient foundations: Retina France, Association Française contre les Myopathies, Union Nationale des Aveugles et Déficients Visuels, Ouvrir Les Yeux and the Association contre les Maladies Mitochondriales.

This work was supported by the INSERM, the CNRS, Université Montpellier I et II, France and the University of Angers, France, and by an European E-Rare program.

\section{Author details}

${ }^{1}$ Institut des Neurosciences de Montpellier, U1051 de I'INSERM, Université de Montpellier I et II, BP 74103, F-34091 Montpellier cedex 05, France. ${ }^{2} \mathrm{CHRU}$

Montpellier, Centre de Référence pour les Maladies Sensorielles Génétiques, Hôpital Gui de Chauliac, F-34295 Montpellier, France. ${ }^{3}$ INSERM U1083, F-49000 Angers, France. ${ }^{4}$ CNRS 6214, F-49000 Angers, France. ${ }^{5}$ Centre Hospitalier Universitaire, F-49000 Angers, France. ${ }^{6}$ Glostrup University Hospital, Copenhagen, Denmark. 
Received: 1 August 2011 Accepted: 15 March 2012

Published: 9 July 2012

\section{References}

1. Kjer P: Infantile optic atrophy with dominant mode of inheritance: a clinical and genetic study of 19 Danish families. Acta Ophthalmol Suppl 1959, 164(Supp 54):1-147.

2. Taban M, Cohen BH, David Rothner A, Traboulsi El: Association of optic nerve hypoplasia with mitochondrial cytopathies. J Child Neurol 2006, 21 (11):956-960.

3. Delettre $C$, Lenaers $G$, Pelloquin L, Belenguer P, Hamel CP: OPA1 (Kjer type) dominant optic atrophy: a novel mitochondrial disease. Mol Genet Metab 2002, 75(2):97-107.

4. Amati-Bonneau P, Milea D, Bonneau D, Chevrollier A, Ferre M, Guillet V, Gueguen N, Loiseau D, de Crescenzo MA, Verny C, et al: OPA1-associated disorders: phenotypes and pathophysiology. Int J Biochem Cell Biol 2009, 41(10):1855-1865.

5. Thiselton DL, Alexander C, Taanman JW, Brooks S, Rosenberg T, Eiberg H, Andreasson S, Van Regemorter N, Munier FL, Moore AT, et al: A comprehensive survey of mutations in the OPA 1 gene in patients with autosomal dominant optic atrophy. Invest Ophthalmol Vis Sci 2002, 43 (6):1715-1724.

6. Yu-Wai-Man P, Griffiths PG, Burke A, Sellar PW, Clarke MP, Gnanaraj L, AhKine D, Hudson G, Czermin B, Taylor RW, et al: The prevalence and natural history of dominant optic atrophy due to OPA1 mutations. Ophthalmology 2010, 117(8):1531-1546.

7. Ferre M, Bonneau D, Milea D, Chevrollier A, Verny C, Dollfus H, Ayuso C, Defoort S, Vignal C, Zanlonghi X, et al: Molecular screening of 980 cases of suspected hereditary optic neuropathy with a report on 77 Novel OPA1 Mutations. Human Mutation 2009, 30(7):E692-E705.

8. Toomes C, Marchbank NJ, Mackey DA, Craig JE, Newbury-Ecob RA, Bennett CP, Vize CJ, Desai SP, Black GC, Patel N, et al: Spectrum, frequency and penetrance of OPA1 mutations in dominant optic atrophy. Hum $\mathrm{Mol}$ Genet 2001, 10(13):1369-1378.

9. Yu-Wai-Man P, Griffiths PG, Gorman GS, Lourenco CM, Wright AF, Auer-Grumbach M, Toscano A, Musumeci O, Valentino ML, Caporali L, et al: Multi-system neurological disease is common in patients with OPA1 mutations. Brain 2010, 133(Pt 3):771-786.

10. Batten B: A family suffering from hereditary optic atrophy. Trans Ophthalmol Soc UK 1896, 16:125.

11. Snell S: Disease of the optic nerve I. hereditary or congenital optic atrophy and allied cases. Trans Ophthalmol Soc UK 1897, 17:66-81.

12. Nettleship E: Bowman lecture: on some hereditary diseases of the eyes. Trans Ophthalmol Soc UK 1909, 29(57):116.

13. Griscom J: Am J Ophthalmol 1921, 5:347.

14. Voisin J, Delthil S: Bull Soc Opht France. 1949, 2

15. Carelli V, La Morgia C, lommarini L, Carroccia R, Mattiazzi M, Sangiorgi S, Farne S, Maresca A, Foscarini B, Lanzi L, et al: Mitochondrial optic neuropathies: how two genomes may kill the same cell type? Bioscience Reports 2007, 27(1-3):173-184.

16. Milea D, Amati-Bonneau P, Reynier P, Bonneau D: Genetically determined optic neuropathies. Curr Opin Neurol 2010, 23(1):24-28.

17. Yu-Wai-Man P, Griffiths PG, Hudson G, Chinnery PF: Inherited mitochondrial optic neuropathies. J Med Genet 2009, 46(3):145-158.

18. Kjer B, Eiberg H, Kjer P, Rosenberg T: Dominant optic atrophy mapped to chromosome $3 q$ region. II. Clinical and epidemiological aspects. Acta Ophthalmol Scandinavica 1996, 74(1):3-7.

19. Cohn AC, Toomes C, Hewitt AW, Kearns LS, Inglehearn CF, Craig JE, Mackey DA: The natural history of OPA1-related autosomal dominant optic atrophy. Br J Ophthalmol 2008, 92(10):1333-1336.

20. Votruba M, Fitzke FW, Holder GE, Carter A, Bhattacharya SS, Moore AT: Clinical features in affected individuals from 21 pedigrees with dominant optic atrophy. Arch Ophthalmol 1998, 116(3):351-358.

21. Votruba M, Moore AT, Bhattacharya SS: Clinical features, molecular genetics, and pathophysiology of dominant optic atrophy. Journal of J Med Genet 1998, 35(10):793-800.

22. Barboni P, Carbonelli M, Savini G, Foscarini B, Parisi V, Valentino ML, Carta A, De Negri A, Sadun F, Zeviani M, et al: OPA1 mutations associated with dominant optic atrophy influence optic nerve head size. Ophthalmology 2011, 117(8):1547-1553.
23. Yu-Wai-Man P, Bailie M, Atawan A, Chinnery PF, Griffiths PG: Pattern of retinal ganglion cell loss in dominant optic atrophy due to OPA1 mutations. Eye (Lond) 2011, 25(5):596-602.

24. Smith DP: Diagnostic criteria in cominantly inherited juvenile optic atrophy. A report of three new families. Am J Optom Physiol Opt Arch Am Acad Optom 1972, 49(3):183-200.

25. Puomila A, Huoponen K, Mantyjarvi M, Hamalainen P, Paananen R, Sankila EM, Savontaus ML, Somer M, Nikoskelainen E: Dominant optic atrophy: correlation between clinical and molecular genetic studies. Acta Opthalmol Scandinavica 2005, 83(3):337-346.

26. Bremner FD, Tomlin EA, Shallo-Hoffmann J, Votruba M, Smith SE: The pupil in dominant optic atrophy. Invest Ophthalmol Vis Sci 2001, 42(3):675-678.

27. La Morgia C, Ross-Cisneros FN, Sadun AA, Hannibal J, Munarini A, Mantovani V, Barboni P, Cantalupo G, Tozer KR, Sancisi E, et al: Melanopsin retinal ganglion cells are resistant to neurodegeneration in mitochondrial optic neuropathies. Brain 2010, 133(Pt 8):2426-2438.

28. Reynier P, Amati-Bonneau P, Verny C, Olichon A, Simard G, Guichet A, Bonnemains C, Malecaze F, Malinge MC, Pelletier JB, et al: OPA3 gene mutations responsible for autosomal dominant optic atrophy and cataract. J Med Genet 2004, 41(9):e110.

29. Cornille K, Milea D, Amati-Bonneau P, Procaccio V, Zazoun L, Guillet V, El Achouri G, Delettre C, Gueguen N, Loiseau D, et al: Reversible optic neuropathy with OPA1 exon 5b mutation. Ann Neurol 2008 63(5):667-671.

30. Nochez Y, Arsene S, Gueguen N, Chevrollier A, Ferre M, Guillet V, Desquiret $V$, Toutain A, Bonneau D, Procaccio V, et al: Acute and late-onset optic atrophy due to a novel OPA1 mutation leading to a mitochondrial coupling defect. Mol Vis 2009, 15:598-608.

31. Amati-Bonneau $P$, Valentino ML, Reynier $P$, Gallardo ME, Bornstein $B$, Boissiere A, Campos Y, Rivera H, de la Aleja JG, Carroccia R, et al: OPA1 mutations induce mitochondrial DNA instability and optic atrophy 'plus' phenotypes. Brain 2008, 131(Pt 2):338-351.

32. Hudson G, Amati-Bonneau P, Blakely EL, Stewart JD, He L, Schaefer AM, Griffiths PG, Ahlqvist K, Suomalainen A, Reynier P, et al: Mutation of OPA1 causes dominant optic atrophy with external ophthalmoplegia, ataxia, deafness and multiple mitochondrial DNA deletions: a novel disorder of mtDNA maintenance. Brain 2008, 131(Pt 2):329-337.

33. Amati-Bonneau P, Guichet A, Olichon A, Chevrollier A, Viala F, Miot S, Ayuso C, Odent S, Arrouet C, Verny C, et al: OPA1 R445H mutation in optic atrophy associated with sensorineural deafness. Ann Neurol 2005, 58 (6):958-963.

34. Amati-Bonneau P, Odent S, Derrien C, Pasquier L, Malthiery Y, Reynier P, Bonneau D: The association of autosomal dominant optic atrophy and moderate deafness may be due to the $\mathrm{R} 445 \mathrm{H}$ mutation in the OPA1 gene. Am J Ophthalmol 2003, 136(6):1170-1171.

35. Li C, Kosmorsky G, Zhang K, Katz BJ, Ge J, Traboulsi El: Optic atrophy and sensorineural hearing loss in a family caused by an R445H OPA1 mutation. American journal of medical genetics 2005, 138A(3):208-211.

36. Payne M, Yang Z, Katz BJ, Warner JE, Weight CJ, Zhao Y, Pearson ED, Treft RL, Hillman T, Kennedy RJ, et al: Dominant optic atrophy, sensorineural hearing loss, ptosis, and ophthalmoplegia: a syndrome caused by a missense mutation in OPA1. Am J Ophthalmol 2004 138(5):749-755.

37. Huang T, Santarelli R, Starr A: Mutation of OPA1 gene causes deafness by affecting function of auditory nerve terminals. Brain Res 2009, 1300:97104.

38. Verny C, Loiseau D, Scherer C, Lejeune P, Chevrollier A, Gueguen N, Guillet $V$, Dubas F, Reynier P, Amati-Bonneau P, et al: Multiple sclerosis-like disorder in OPA1-related autosomal dominant optic atrophy. Neurology 2008, 70(13 Pt 2):1152-1153.

39. Pretegiani E, Rufa A, Gallus GN, Cardaioli E, Malandrini A, Federico A: Spastic paraplegia in 'dominant optic atrophy plus' phenotype due to OPA1 mutation. Brain 2011, 134(Pt 11):e195.

40. Marelli C, Amati-Bonneau P, Reynier P, Layet V, Layet A, Stevanin G, Brissaud E, Bonneau D, Durr A, Brice A: Heterozygous OPA1 mutations in Behr syndrome. Brain 2011, 134(Pt 4):e169.

41. Schaaf CP, Blazo M, Lewis RA, Tonini RE, Takei H, Wang J, Wong LJ, Scaglia F: Early-onset severe neuromuscular phenotype associated with compound heterozygosity for OPA1 mutations. Mol Genet Metab 2011, 103(4):383-387. 
42. Eiberg $H$, Kjer $B$, Kjer $P$, Rosenberg $T$ : Dominant optic atrophy (OPA1) mapped to chromosome $3 q$ region. I. Linkage analysis.Hum Mol Genet 1994, 3(6):977-980

43. Bonneau D, Souied E, Gerber S, Rozet JM, D'Haens E, Journel H, Plessis G, Weissenbach J, Munnich A, Kaplan J: No evidence of genetic heterogeneity in dominant optic atrophy. J Med Genet 1995, 32(12):951953.

44. Alexander C, Votruba M, Pesch UE, Thiselton DL, Mayer S, Moore A, Rodriguez M, Kellner U, Leo-Kottler B, Auburger G, et al: OPA1, encoding a dynamin-related GTPase, is mutated in autosomal dominant optic atrophy linked to chromosome 3q28. Nature Genet 2000, 26(2):211-215.

45. Delettre C, Lenaers G, Griffoin JM, Gigarel N, Lorenzo C, Belenguer P, Pelloquin L, Grosgeorge J, Turc-Carel C, Perret E, et al: Nuclear gene OPA1, encoding a mitochondrial dynamin-related protein, is mutated in dominant optic atrophy. Nature Genet 2000, 26(2):207-210.

46. Kerrison JB, Arnould VJ, Ferraz Sallum JM, Vagefi MR, Barmada MM, Li Y, Zhu $\mathrm{D}$, Maumenee $\mathrm{H}$ : Genetic heterogeneity of dominant optic atrophy, Kjer type: Identification of a second locus on chromosome 18q12.2-12.3. Arch Ophthalmol 1999, 117(6):805-810

47. Barbet F, Hakiki S, Orssaud C, Gerber S, Perrault I, Hanein S, Ducroq D, Dufier $J$, Munnich A, Kaplan J, et al: A third locus for dominant optic atrophy on chromosome 22q. J Med Genet 2005, 42(1):e1.

48. Assink JJ, Tijmes NT, ten Brink JB, Oostra RJ, Riemslag FC, de Jong PT, Bergen AA: A gene for $X$-linked optic atrophy is closely linked to the Xp11.4-Xp11.2 region of the X chromosome. Am J Hum Genet 1997, 61 (4):934-939.

49. Katz BJ, Zhao Y, Warner JE, Tong Z, Yang Z, Zhang K: A family with $X$-linked optic atrophy linked to the OPA2 locus Xp11.4-Xp11.2. American Am J Med Genet 2006, 140(20):2207-2211.

50. Barbet F, Gerber S, Hakiki S, Perrault I, Hanein S, Ducroq D, Tanguy G, Dufier $J$, Munnich A, Rozet JM, et al: A first locus for isolated autosomal recessive optic atrophy (ROA1) maps to chromosome 8q. Eur J Hum Genet 2003, 11(12):966-971.

51. Hanein S, Perrault I, Roche O, Gerber S, Khadom N, Rio M, Boddaert N, JeanPierre M, Brahimi N, Serre V, et al: TMEM126A, encoding a mitochondrial protein, is mutated in autosomal-recessive nonsyndromic optic atrophy. Am J Hum Genet 2009, 84(4):493-498.

52. Anikster Y, Kleta R, Shaag A, Gahl WA, Elpeleg O: Type III 3-methylglutaconic aciduria (optic atrophy plus syndrome, or Costeff optic atrophy syndrome): identification of the OPA3 gene and its founder mutation in Iraqi Jews. Am J Hum Genet 2001, 69(6):1218-1224

53. Carelli V, Schimpf S, Fuhrmann N, Valentino ML, Zanna C, Iommarini L, Papke M, Schaich S, Tippmann S, Baumann B, et al: A clinically complex form of dominant optic atrophy (OPA8) maps on chromosome 16. Hum Mol Genet 2011, 20(10):1893-905.

54. Da Cruz S, Xenarios I, Langridge J, Vilbois F, Parone PA, Martinou JC: Proteomic analysis of the mouse liver mitochondrial inner membrane. $J$ Biol Chem 2003, 278(42):41566-41571.

55. Olichon A, Emorine LJ, Descoins E, Pelloquin L, Brichese L, Gas N, Guillou E, Delettre C, Valette A, Hamel CP, et al: The human dynamin-related protein OPA 1 is anchored to the mitochondrial inner membrane facing the inter-membrane space. FEBS letters 2002, 523(1-3):171-176.

56. Pierron D, Ferre $M$, Rocher $C$, Chevrollier A, Murail $P$, Thoraval D, AmatiBonneau P, Reynier P, Letellier T: OPA1-related dominant optic atrophy is not strongly influenced by mitochondrial DNA background. Med Genet 2009, 10:70

57. Chevrollier A, Guillet V, Loiseau D, Gueguen N, de Crescenzo MA, Verny C, Eng MF, Dollfus H, Odent S, Milea D, et al: Hereditary optic neuropathies share a common mitochondrial coupling defect. Ann Neurol 2008, 63 (6):794-798.

58. Olichon A, Landes T, Arnaune-Pelloquin L, Emorine $L$, Mils V, Guichet A, Delettre C, Hamel C, Amati-Bonneau P, Bonneau D, et al: Effects of OPA1 mutations on mitochondrial morphology and apoptosis: relevance to ADOA pathogenesis. J Cell Physiol 2007, 211(2):423-430.

59. Zanna C, Ghelli A, Porcelli AM, Karbowski M, Youle RJ, Schimpf S, Wissinger B, Pinti M, Cossarizza A, Vidoni S, et al: OPA1 mutations associated with dominant optic atrophy impair oxidative phosphorylation and mitochondrial fusion. Brain 2008, 131(Pt 2):352-367.

60. Lenaers $G$, Reynier P, Elachouri G, Soukkarieh C, Olichon A, Belenguer P, Baricault L, Ducommun B, Hamel C, Delettre C: OPA1 functions in mitochondria and dysfunctions in optic nerve. Int J Biochem Cell Biol 2009, 41(10):1866-1874.

61. Olichon A, Baricault L, Gas N, Guillou E, Valette A, Belenguer P, Lenaers G: Loss of OPA1 perturbates the mitochondrial inner membrane structure and integrity, leading to cytochrome c release and apoptosis. J Biol Chem 2003, 278(10):7743-7746.

62. Griparic L, van der Wel NN, Orozco IJ, Peters PJ, van der Bliek AM: Loss of the intermembrane space protein Mgm1/OPA1 induces swelling and localized constrictions along the lengths of mitochondria. J Bio/ Chem 2004, 279(18):18792-18798.

63. Elachouri G, Vidoni S, Zanna C, Pattyn A, Boukhaddaoui H, Gaget K, Yu-WaiMan P, Gasparre G, Sarzi E, Delettre C, et al: OPA1 links human mitochondrial genome maintenance to mtDNA replication and distribution. Genome Res 2011, 21(1):12-20.

64. Olichon A, Elachouri G, Baricault L, Delettre C, Belenguer P, Lenaers G: OPA1 alternate splicing uncouples an evolutionary conserved function in mitochondrial fusion from a vertebrate restricted function in apoptosis. Cell Death Differ 2007, 14(4):682-692.

65. Dayanithi G, Chen-Kuo-Chang M, Viero C, Hamel C, Muller A, Lenaers G: Characterization of $\mathrm{Ca} 2+$ signalling in postnatal mouse retinal ganglion cells: involvement of OPA1 in Ca2+ clearance. Ophthalmic Genet 2010, 31 (2):53-65.

66. Spinazzi M, Cazzola S, Bortolozzi M, Baracca A, Loro E, Casarin A, Solaini G, Sgarbi G, Casalena G, Cenacchi G, et al: A novel deletion in the gtpase domain of OPA 1 causes defects in mitochondrial morphology and distribution, but not in function. Hum Mol Genet. 2008, 17(21):3291-3302

67. Yu-Wai-Man P, Trenell MI, Hollingsworth KG, Griffiths PG, Chinnery PF: OPA1 mutations impair mitochondrial function in both pure and complicated dominant optic atrophy. Brain 2010.

68. Andrews RM, Griffiths PG, Johnson MA, Turnbull DM: Histochemical localisation of mitochondrial enzyme activity in human optic nerve and retina. $\mathrm{Br} J$ Ophthalmol 1999, 83(2):231-235.

69. Bristow EA, Griffiths PG, Andrews RM, Johnson MA, Turnbull DM: The distribution of mitochondrial activity in relation to optic nerve structure. Arch Ophthalmol 2002, 120(6):791-796.

70. Wang L, Dong J, Cull G, Fortune B, Cioffi GA: Varicosities of intraretinal ganglion cell axons in human and nonhuman primates. Invest Ophthalmol Vis Sci 2003, 44(1):2-9.

71. Yu Wai Man CY, Chinnery PF, Griffiths PG: Optic neuropathies--importance of spatial distribution of mitochondria as well as function. Medical hypotheses 2005, 65(6):1038-1042.

72. Osborne NN, Li GY, Ji D, Mortiboys HJ, Jackson S: Light affects mitochondria to cause apoptosis to cultured cells: possible relevance to ganglion cell death in certain optic neuropathies. J Neurochem 2008, 105 (5):2013-2028

73. Alavi MV, Bette S, Schimpf S, Schuettauf F, Schraermeyer U, Wehrl HF, Ruttiger L, Beck SC, Tonagel F, Pichler BJ, et al: A splice site mutation in the murine Opa1 gene features pathology of autosomal dominant optic atrophy. Brain 2007, 130(Pt 4):1029-1042.

74. Davies VJ, Hollins AJ, Piechota MJ, Yip W, Davies JR, White KE, Nicols PP, Boulton ME, Votruba M: Opa1 deficiency in a mouse model of autosomal dominant optic atrophy impairs mitochondrial morphology, optic nerve structure and visual function. Hum Mol Genet 2007, 16(11):1307-1318.

75. Heiduschka P, Schnichels S, Fuhrmann N, Hofmeister S, Schraermeyer U, Wissinger B, Alavi MV: Electrophysiological and histologic assessment of retinal ganglion cell fate in a mouse model for OPA1-associated autosomal dominant optic atrophy. Invest Ophthalmol Vis Sci 2010, 51 (3):1424-1431.

76. Barnard AR, Charbel Issa P, Perganta G, Williams PA, Davies VJ, Sekaran S, Votruba M, Maclaren RE: Specific deficits in visual electrophysiology in a mouse model of dominant optic atrophy. Exp Eye Res 2011, 93(5):771-77.

77. Williams PA, Morgan JE, Votruba M: Opa1 deficiency in a mouse model of dominant optic atrophy leads to retinal ganglion cell dendropathy. Brain 2010, 133(10):2942-51.

78. White KE, Davies V, Hogan V, Piechota M, Nichols P, Turnbull DM, Votruba M: OPA1 deficiency is associated with increased autophagy in retinal ganglion cells in a murine model of dominant optic atrophy. Invest Ophthalmol Vis Sci 2009, 50(6):2567-2571. 
79. Alavi MV, Fuhrmann N, Nguyen HP, Yu-Wai-Man P, Heiduschka P, Chinnery PF, Wissinger B: Subtle neurological and metabolic abnormalities in an Opa1 mouse model of autosomal dominant optic atrophy. Exp Neurol 2009, 220(2):404-409.

80. Votruba M, Thiselton D, Bhattacharya SS: Optic disc morphology of patients with OPA1 autosomal dominant optic atrophy. Br J Ophthalmol 2003, 87(1):48-53.

81. Milea D, Sander B, Wegener M, Jensen $H$, Kjer B, Jorgensen TM, Lund-Andersen $\mathrm{H}$, Larsen M: Axonal loss occurs early in dominant optic atrophy. Acta Ophthalmol 2010, 88(3):342-346.

82. Alward WL: The OPA1 gene and optic neuropathy. Br J Ophthalmol 2003, 87(1):2-3.

83. Holder GE, Votruba M, Carter AC, Bhattacharya SS, Fitzke FW, Moore AT: Electrophysiological findings in dominant optic atrophy (DOA) linking to the OPA1 locus on chromosome 3q 28-qter. Doc Ophthalmol 1998, 95(3-4):217-228.

84. Fuhrmann N, Alavi MV, Bitoun P, Woernle S, Auburger G, Leo-Kottler B, YuWai-Man P, Chinnery P, Wissinger B: Genomic rearrangements in OPA1 are frequent in patients with autosomal dominant optic atrophy. J Med Genet 2009, 46(2):136-144.

85. Fuhrmann N, Schimpf S, Kamenisch Y, Leo-Kottler B, Alexander C, Auburger G, Zrenner E, Wissinger B, Alavi MV: Solving a 50 year mystery of a missing OPA1 mutation: more insights from the first family diagnosed with autosomal dominant optic atrophy. Mol Neurodegener 2010, 5:25.

86. Almind GJ, Gronskov K, Milea D, Larsen M, Brondum-Nielsen K, Ek J: Genomic deletions in OPA1 in Danish patients with autosomal dominant optic atrophy. BMC Med Genet 2011, 12(1):49.

87. Yu-Wai-Man P, Stewart JD, Hudson G, Andrews RM, Griffiths PG, Birch MK, Chinnery PF: OPA1 increases the risk of normal but not high tension glaucoma. J Med Genet 2010, 47(2):120-125.

88. Volker-Dieben HJ, Went LN, de Vries-de Mol EC: Comparative colour vision and other ophthalmological studies in three families with dominant inherited juvenile optic atrophy. Mod Probl Ophthalmol 1974, 13(0):277-281

89. Went LN, De Vries-De Mol EC, Volker-Dieben HJ: A family with apparently sex-linked optic atrophy. J Med Genet 1975 12(1):94-98

90. Yu-Wai-Man P, Griffiths PG, Chinnery PF: Mitochondrial optic neuropathies Disease mechanisms and therapeutic strategies. Prog Retin Eye Res 2010, 30(2):81-114.

91. Barrett TG, Bundey SE: Wolfram (DIDMOAD) syndrome. J Med Genet 1997, 34(10):838-841.

92. Barrett TG, Bundey SE, Fielder AR, Good PA: Optic atrophy in Wolfram (DIDMOAD) syndrome. Eye (Lond) 1997. 11(Pt 6):882-888.

93. Eiberg H, Hansen L, Kjer B, Hansen T, Pedersen O, Bille M, Rosenberg T, Tranebjaerg L: Autosomal dominant optic atrophy associated with hearing impairment and impaired glucose regulation caused by a missense mutation in the WFS1 gene. J Med Genet 2006, 43(5):435-440.

94. Rendtorff ND, Lodahl M, Boulahbel $H$, Johansen IR, Pandya A, Welch KO, Norris WW, Arnos KS, Bitner-Glindzicz M, Emery SB, et al: Identification of $p$. A684V missense mutation in the WFS1 gene as a frequent cause of autosomal dominant optic atrophy and hearing impairment. Am J Med Genet 2011, 155A(6):1298-1313.

95. Kleta R, Skovby F, Christensen E, Rosenberg T, Gahl WA, Anikster Y: 3-Methylglutaconic aciduria type III in a non-Iraqi-Jewish kindred: clinical and molecular findings. Mol Genet Metab 2002, 76(3):201-206.

96. Voo I, Allf BE, Udar N, Silva-Garcia R, Vance J, Small KW: Hereditary motor and sensory neuropathy type VI with optic atrophy. Am J Ophthalmol 2003, 136(4):670-677.

97. Zuchner S, De Jonghe P, Jordanova A, Claeys KG, Guergueltcheva V, Cherninkova S, Hamilton SR, Van Stavern G, Krajewski KM, Stajich J, et al: Axonal neuropathy with optic atrophy is caused by mutations in mitofusin 2. Ann Neurol 2006, 59(2):276-281.

98. Rouzier C, Bannwarth S, Chaussenot A, Chevrollier A, Verschueren A, Bonello-Palot N, Fragaki K, Cano A, Pouget J, Pellissier JF, et al: The MFN2 gene is responsible for mitochondrial DNA instability and optic atrophy 'plus' phenotype. Brain 2012, 135:23-34.
99. Tranebjaerg L, Schwartz C, Eriksen H, Andreasson S, Ponjavic V, Dahl A, Stevenson RE, May M, Arena F, Barker D, et al: A new $\mathrm{X}$ linked recessive deafness syndrome with blindness, dystonia, fractures, and mental deficiency is linked to Xq22. J Med Genet 1995, 32(4):257-263.

100. Jin H, May M, Tranebjaerg L, Kendall E, Fontan G, Jackson J, Subramony SH, Arena F, Lubs H, Smith S, et al: A novel X-linked gene, DDP, shows mutations in families with deafness (DFN-1), dystonia, mental deficiency and blindness. Nat Genet 1996, 14(2):177-180.

101. Milone M, Younge BR, Wang J, Zhang S, Wong LJ: Mitochondrial disorder with OPA1 mutation lacking optic atrophy. Mitochondrion 2009, 9(4):279-281.

doi:10.1186/1750-1172-7-46

Cite this article as: Lenaers et al:: Dominant optic atrophy. Orphanet Journal of Rare Diseases 2012 7:46.

\section{Submit your next manuscript to BioMed Central and take full advantage of:}

- Convenient online submission

- Thorough peer review

- No space constraints or color figure charges

- Immediate publication on acceptance

- Inclusion in PubMed, CAS, Scopus and Google Scholar

- Research which is freely available for redistribution 